Running head: Self-harm in LGB Students

\title{
Psychological correlates of self-harm within gay, lesbian and bisexual UK University students
}

\author{
Dr. Peter Taylor*1, Dr Katie Dhingra², Assoc. Prof. Joanne \\ Dickson $^{3}$, Dr Elizabeth McDermott ${ }^{4}$
}

${ }^{1}$ Division of Psychology \& Mental Health, School of Health Sciences, University of Manchester, UK

${ }^{2}$ School of Social Sciences, Leeds Beckett University, UK.

3 Department of Psychology, School of Arts and Humanities, Edith Cowan University, Australia

${ }^{4}$ Faculty of Medicine \& Health, University of Lancaster, UK

Word count (exc. figures/tables): 4451 


\begin{abstract}
Objective: This study explores the association between Lesbian, Gay or Bisexual (LGB) status and self-harm in UK higher education students. There is currently limited data on this association, and the role psychological variables have in potentially explaining this link, in UK students. We examine whether LGB status is associated with self-harm (both nonsuicidal self-injury [NSSI] and suicide attempts [SA]), and whether four psychological variables (depression, anxiety, belongingness, self-esteem) mediate this association. Design: Cross-sectional survey. Method: UK university students (n=707) completed an online survey including measures of self-harm, affective symptoms, belongingness, and self-esteem. Latent Variable Modelling (LVM) was used to test our hypotheses. Results: LGB status remained associated with an elevated risk of NSSI and SA even after accounting for mediating factors. Self-esteem and (in the case of SA but not NSSI) thwarted belongingness, did, however, explain some of this association and were correlated with self-harm risk. Conclusions: The findings suggest that psychological factors may account for the association between LGB status and self-harm and, as such, prevention and intervention efforts directed at these psychological mediators may help to reduce self-harm risk in this population.
\end{abstract}

Keywords: LGB, Self-harm, Lesbian, Gay, Bisexual, Self-esteem 


\section{Psychological correlates of self-harm within gay, lesbian and bisexual UK University students}

People who are Lesbian, Gay or Bisexual (LGB), are at considerably elevated risk of self-harm, including both Non-Suicidal Self-Injury (NSSI; Odds Ratio = 3.00; Batejan, Jarvi, \& Swenson, 2015), and Suicide Attempts (SA; Odds Ratio = 2.26; Miranda-Mendizábal et al., 2017). LGB young people and students appear particularly at risk (Batejan et al., 2015; Haas et al., 2011; McDermott, Hughes, \& Rawlings, 2017). This research has predominantly taken place in the US but a smaller number of studies conducted in the UK population do also suggest greater risk of self-harm for LGB young people or students (Warner et al., 2004; Young, Riordan, \& Stark, 2011). Within this population, bisexual individuals appear particularly at risk (Batejan et al., 2015). Further research in UK LGB student populations is still needed. Currently, whilst LGB individuals are known to be a high-risk group, there is less research focused on the psychological variable that may help explain this risk (Batejan et al., 2015; Miranda-Mendizábal et al., 2017). In particular data from UK higher-education students that assesses the association between LGB status, self-harm, and hypothesised psychological mediators, is limited. The current study therefore examines the association between LGB status and self-harm (both NSSI and SA) in students, and investigates the extent to which four psychological variables (depression, anxiety, belongingness, selfesteem) may account for this association. This project is consistent with the UK governments focus on mental health in young people, which emphasises a greater focus on highereducation students (Department of Health \& Department of Education, 2017).

Self-harm is an umbrella term covering acts of intentional self-injury irrespective of suicidal intent (Hawton, Rodham, Evans, \& Weatherall, 2002; National Collaborating Centre for Mental Health, 2004). Under this umbrella are SAs (acts of self-harm where the intention was to end one's life) and NSSI (acts of self-harm where the intention to end one's life was 
absent). Importantly, there is debate about whether it is feasible or meaningful to distinguish between NSSI and SA (Butler \& Malone, 2013; Kapur, Cooper, O'Connor, \& Hawton, 2013). In the current study we consider both outcomes, allowing us to test whether converging or conflicting findings emerge. Self-harm (both NSSI and SA) is problematic because it is a major predictor of death by suicide (Hawton et al., 2015; Ribeiro et al., 2016), overall mortality (Bergen et al., 2012), and also often a marker of substantial distress and clinical need (Goldman-Mellor et al., 2014; Hasking, Momeni, Swannell, \& Chia, 2008; Reinherz et al., 1995). National suicide prevention guidelines emphasise a need to focus on high risk groups, including the LGB population (Department of Health, 2017).

A Minority stress framework (Meyer, 2003) may have theoretical utility in developing an explanation for the high prevalence of self-harm among LGB people. According to minority stress theory, LGB people are stigmatized as a result of their minority status, and consequently experience disproportionately high levels of social and individual stressors (e.g., discrimination, sexuality-related micro-aggression and victimisation, and increased vigilance and expectation of rejection; Lambe, Cerezo, \& O'Shaughnessy, 2017; Pitoňák, 2017; Sowe, Taylor, \& Brown, 2017; Sue, 2010; Ybarra, Mitchell, Palmer, \& Reisner, 2015). Elevated stress, in turn, has a severe negative impact on the health and wellbeing of LGB people (Meyer, 2003), and may account for adverse outcomes such as an increased prevalence of self-harm (Muehlenkamp, Hilt, Ehlinger, \& McMillan, 2015). This framework has been extended to consider the importance of psychological mediating variables in explaining the link between minority stress and adverse outcomes like self-harm.

(Hatzenbuehler, 2009; Meyer, 2003; Pitoňák, 2017).

We can contrast this framework with recent theoretical models of self-harm, to help identify common psychological process that might help explain how LGB status, and the social adversities associated with this, may result in self-harm. The recent cognitive- 
emotional model of self-injury (Hasking, Whitlock, Voon \& Rose, 2017) specifies selfschema or self-concept as an important distal process conferring vulnerability to self-injury. This also overlaps with the minority stress theory framework, where self-concept (i.e. discontent or lack of acceptance with who one is) and the internalising of negative perceptions of LGB status is identified as an important mediating process (Hatzenbuehler, 2009). Thus, whilst a range of psychological processes may be relevant here, the way in which LGB individuals feel about themselves seems particularly important. Rejection, discrimination, and exposure to negative attitudes and stereotypes may affect the self-concept and self-esteem of LGB individuals (Hegna \& Wichstrøm, 2007; Kashubeck-West, Szymanski, \& Meyer, 2008; Pitoňák, 2017; Sowe et al., 2017). Low self-esteem, encompassing the extent to which a person accepts, likes or is satisfied with themselves, is associated with a greater risk of self-harm, both cross-sectionally and longitudinally (Forrester, Slater, Jomar, Mitzman, \& Taylor, 2017; Hegna \& Wichstrøm, 2007; McGee \& Williams, 2000; Tatnell, Kelada, Hasking, \& Martin, 2014). In a recent meta-analysis individuals with a history of NSSI reported poorer self-esteem than non-NSSI samples $(d=$ 0.59-0.78; Forrester et al., 2017), with a more pronounced difference for more active and self-critical forms of self-perception. Low self-esteem is associated with suicidal ideation and behaviour in LGB individuals (Hegna \& Wichstrøm, 2007; Ybarra et al., 2015). Self-harm may occur as a means of coping with, avoiding or escaping from highly aversive internal states, including chronically low self-esteem (Rasmussen, Hawton, Philpott-Morgan, \& O'Connor, 2016; Taylor et al., 2018). For NSSI, more specifically, motives of selfpunishment are highly endorsed (41-62\% of people who engage in NSSI; Taylor et al., 2018). NSSI with this function may emerge in those with a particularly critical self-perception. A second influential model of both suicidal behaviour and self-harm broadly, the Interpersonal-Psychological Theory of suicide (IPTS; Van Orden, Witte, Gordon, Bender, \& 
Joiner, 2008; Van Orden et al., 2010), seems particularly compatible with the minority stress model due to its shared focus on interpersonal factors. The IPTS proposes that the serious desire for death by suicide arises from the co-occurrence of two proximal, causal factors: (1) perceived burdensomeness (an individual's sense that he or she is a liability to others and worth more dead than alive) and (2) thwarted belongingness (an individual's sense that he or she lacks meaningful connections to others). For LGB individuals, the need to belong may be thwarted by experiences of rejection or loss of contact with social groups and communities that a person may have formerly been a part of. This construct of thwarted belongingness also mirrors suggestions that social exclusion, rejection or a general loss of social connections may represent an important facet of minority stress (Hatzenbuehler, 2009). Thus, this sense of thwarted belongingness could be a key modifiable psychological concomitant of the social challenges LGB individuals face. Thwarted belongingness is associated with suicidal thinking and behaviour (Chu et al., 2017; Van Orden et al., 2010; Van Orden, Witte, Gordon, Bender, \& Joiner, 2008) as well as NSSI (Assavedo \& Anestis, 2016). However, whether this construct accounts for the increased risk of self-harm in LGB individuals is unclear. Fostering belongingness amongst LGB individuals has been suggested as a means of increasing resilience to difficulties including self-harm (Aranmolate, Bogan, Tiffany Hoard, \& Mawsomolate, 2017; McLaren, 2016), but studies in LGB individuals, have had mixed results regarding whether belongingness is associated with suicidal ideation (Baams, Grossman, \& Russell, 2015; Cramer, Stroud, Fraser, \& Graham, 2014; Hill \& Pettit, 2012; Woodward, Wingate, Gray, \& Pantalone, 2014).

An increased exposure to emotional distress, including symptoms of depression and anxiety, has been observed in LGB individuals. For example, in combined data from 12 national UK surveys LGB status was associated with an increased risk of common mental disorder symptoms (though findings were more mixed when alternate measures of symptoms 
were adopted; Semlyen, King, Varney, \& Hagger-Johnson, 2016). Greater levels of depression and anxiety are both also risk factors for self-harm (Fox et al., 2015). Hence, the relationship that depressive and anxiety symptoms have with self-harm in LGB students should also be taken into account.

Data regarding the association between LGB status and self-harm in UK students, and the psychological variables that mediate this link, is limited. Whilst measures to tackle the social adversities associated with LGB status are essential, psychological variables, when they can be modified, may also provide a target for therapeutic interventions and preventive strategies. Based on a consideration of the minority stress framework and models of selfharm, self-esteem and thwarted belongingness were identified as two key psychological variables, and so are the focus of this study. The aim of this study was to first examine the association between LGB status and two forms of self-harm in a UK student population, NSSI and SA, and second to explore whether four putative psychological mediators might explain this association. We hypothesised that the association between LGB status and selfharm will be fully accounted for by the psychological mediators, each of which will have an independent association with self-harm.

\section{Method}

\section{Sample}

Participants were university students aged 18 years or older, recruited from various faculties across two UK universities.

\section{Measures}

Sexual orientation. Sexual orientation was assessed using a single item (Haseldon \& Joloza, 2009) which asked, "how would you describe your sexual orientation? Response options were: "heterosexual/straight," "gay/lesbian," "bisexual," or "sexual orientation not specified". 
Anxiety and Depression. The Hospital Anxiety and Depression Scale (HADS; Zigmond \& Snaith, 1983) was employed to measure anxiety and depression. The scale consists of 14 questions, of which seven correspond to the anxiety subscale (e.g. "Worrying thoughts go through my mind") and seven correspond to the depression subscale (e.g. "I have lost interest in my appearance"). Items are rated on a 0-3 point ordinal scale indicating strength of agreement with each item. To reduce the risk of a false positive bias, the HADS does not assess symptoms of anxiety and depression related to physical disorder, such as fatigue and insomnia. The measure has been shown to have adequate diagnostic accuracy. A meta-analysis of diagnostic test accuracy studies reported that, using a cut-score of 8 or more, the HADS depression scale gave $82 \%$ sensitivity and $74 \%$ specificity for detecting major depressive disorder; and the anxiety scale gave $78 \%$ sensitivity and $74 \%$ specificity for detecting generalised anxiety disorder (Brennan, Worrall-Davies, McMillan, Gilbody, \& House, 2010). Internal consistency was good for the anxiety, $\alpha=.83$, and depression subscales,$\alpha=.82$, in the current sample.

Thwarted Belongingness. Thwarted belongingness was assessed with 7-items taken from the Interpersonal Needs Questionnaire (Van Orden, Cukrowicz, Witte, \& Joiner, 2012). The scale measures participants' beliefs about the extent to which they feel connected to others in a frequent and caring way. A sample item is "These days other people care about me." Level of agreement on each item is rated with a 7-point scale ranging from 1 ("not at all true of me") to 7 ("very true of me"). Higher scores indicate greater levels of thwarted belongingness. The INQ thwarted belongingness exhibits strong convergent validity with measures of related constructs, such as loneliness, social support and social worth, and demonstrates consistent factor loading across a variety of samples including outpatients, undergraduates, and the elderly (Van Orden et al., 2012). Moreover, a recent study in a large sample of undergraduates found that the factor structure of the scale does not vary between 
genders and shows strong internal consistency and construct validity (Freedenthal, Lamis, Osman, Kahlo, \& Gutierrez, 2011). Internal consistency was good in the current sample, $\alpha=$ 87 .

Suicide Attempts. Suicide attempts were recorded if a respondent answered 'yes' to the following question taken from The Self-Injurious Thoughts and Behaviours Interview (SITBI; Nock, Holmberg, Photos, \& Michel, 2007): "Have you ever made an actual attempt to kill yourself in which you had at least some intent to die?". The SITBI suicide attempt subscale has demonstrated strong inter-rater reliability (average $\mathrm{k}=0.99$ ), test-retest reliability (average $\mathrm{k}=0.70$ ), and construct validity, as demonstrated by strong relations with other measures of suicide attempt $(r=.65$; Nock et al., 2007).

Non-suicidal Self-injury. NSSI behaviour was recorded if a respondent answered 'yes' to the following question taken from the SITBI (Nock et al., 2007): "Have you actually purposely hurt yourself without wanting to die?"

Self-Esteem. Five items drawn from the Internal Protective subscale of the Suicide Resilience Inventory 25 (SRI-25; Osman et al., 2004) were used to index self-esteem: item 1 (“there are many things that I like about myself"), item 5 ("I like myself"), item 13 (“I am proud of many good things about myself"), item 20 ("Regardless of the problem situation I face, I can be happy with myself”), and item 25 (“I feel cheerful about myself”). These items were selected based on their comparability with the Rosenberg Self-Esteem Scale (Rosenberg, 1965). The Internal Protective subscale was originally developed to assess people's satisfaction with life and positive feelings or beliefs about themselves. The remaining three items from this subscale were not so clearly indicators of self-esteem ("Most of the time I set goals that are reasonable for me to meet"; "I am satisfied with most things in my life", "I feel that I am an emotionally strong person"). Items are rated on a 6-point scale, from 1 ("strongly disagree") to 6 ("strongly agree"). The five-item scale fit the data well as 
part of our measurement model (see below). Internal consistency was good in the current sample, $\alpha=.94$.

\section{Procedure}

The research protocol was reviewed and approved by the institutional ethics panels of each participating university. Participants were recruited via an email invite to participate in a study of suicide. Within this email it was made clear to potential participants that they did not need to have experienced suicidal thoughts and behaviours to take part. The study was also advertised on the websites of both universities. Participants completed the study online using Qualtrics, a Web interface that allows for secure remote data collection through the distribution of anonymous secure links to the protocol. Participants were required to consent before the survey was presented online. Participation in the current study was voluntary and no inducements or obligations were used. All participants were debriefed and given phone numbers for local mental health services.

\section{Statistical Analysis}

Latent Variable Modelling (LVM) was used to test our hypotheses. The analysis featured a single binary outcome (NSSI or SA), one binary predictor (LGB or non-LGB status), and four latent mediators (anxiety and depressive symptoms, thwarted belongingness, and self-esteem). Both the anxiety and depressive symptoms scale (HADS) items used a fourpoint response format that is better seen as ordered categorical rather than continuous. In order to simplify the model being estimated, we created item parcels to act as indicators for these two latent variables, which could then be treated as continuous. Item parcels are appropriate here since the latent structure of the measures used are well established, and the focus of the research was not on testing the factor structure of these constructs (Little, Cunningham, Shahar, \& Widaman, 2002; Little, Rhemtulla, Gibson, \& Schoemann, 2013). In this context, item parcelling can reduce error that could otherwise affect model fit without 
biasing structural parameters within the model. For both these latent variables, three item parcels were generated via the correlational method (Little et al., 2013). The thwarted belongingness and self-esteem scales used longer item response formats (six and sevenpoint), which we treated as continuous, and so did not parcel.

The analyses were conducted in Mplus 7.4 (Muthén \& Muthén, 1998-2012) and estimated with Robust Maximum Likelihood (RML; Satorra \& Bentler, 1994; Yuan \& Bentler, 2000) to adjust for the non-normality in the variables. RML can also accommodate binary outcomes via a numerical integration algorithm (Muthén \& Muthén, 1998-2012) and allows the estimation of Odds Ratios (ORs) for these associations within a logistic regression framework, which is helpful for judging effect size. Missing data in endogenous variables is handled as part of the RML estimation meaning that incomplete cases can contribute to the analysis.

We ran two separate series of models with either NSSI or SA as the outcome. We chose to do this rather than co-vary for the influence of one of these outcomes upon the other in the same model. This was driven by awareness of the controversy surrounding the distinction between NSSI and SA (Butler \& Malone, 2013; Kapur et al., 2013) and a concern about partialling out too much variance in an outcome by including a heavily overlapping covariate in the same model.

The models were developed in an iterative manner. Initially a measurement model was estimated to ensure the four latent variables (anxiety and depressive symptoms, thwarted belongingness, self-esteem) fit the data adequately. In Model 1, the direct association between LGB status (binary variable) and self-harm (NSSI or SA) was analysed, excluding indirect effects. In Model 2, indirect effects mediated via thwarted belongingness and selfesteem were included, and the direct path between LGB status and self-harm was fixed to zero. Model 3 extends Model 2 by freeing the association between LGB status and self-harm, 
allowing both direct and indirect effects. Model 4 then extends Model 3 by also including anxiety and depressive symptoms as mediators of the relationship between LGB status and self-harm. The four models are nested, allowing direct comparison.

The fit of the measurement model to the data could be judged with standard criteria including the Confirmatory Fit Index (CFI; adequate fit $>.90$, good fit $>.95)$, Tucker-Lewis Index (TLI; adequate fit > .90, good fit > .96), the Root Mean Squared Residual (RMSEA; adequate fit $<.08$, good fit $<.06$ with the upper confidence interval $<.08)$ and the Standardised Root Mean Square Residual (SRMR; good fit < .09; Byrne, 2001; Hu \& Bentler, 1999; Kline, 2011). Because of the inclusion of a binary outcomes variable, standard LVM fit indices could not be generated for Models 1 to 4. Instead the adjusted Akaike's Information Criterion (AICc) and Bayesian Information Criterion (BIC) were used to compare models, with smaller values indicating better fitting models (Burnham \& Anderson, 2004; Enders \& Tofighi, 2008).

Within the main analysis we combine individuals who report being gay, bisexual or lesbian into a single category, due to the smaller numbers within the sub-categories.

\section{Results}

\section{Sample Characteristics}

Missing data was minimal ( 0.1 to $4.9 \%$ per variable). There was no missing data for $n$ $=627$ participants. The largest pattern of missing data was for participants missing responses for the second thwarted belongingness item only. The sample were aged 18 to 60 years $(M=$ 23.05, SD $=7.15)$ and was predominantly female $(n=552,75.2 \%)$ and White $(n=609$, 83.0\%). The remaining participants were Asian $(n=58,7.9 \%)$, Mixed ethnicity $(n=34$,

$4.6 \%)$, Black ( $n=24,3.3 \%)$, or other $(n=8,1.1 \%$; missing for one person). Gay or bisexual orientation was reported for $119(16.2 \%)$ of participants $($ gay/lesbian $=37$; bisexual $=82)$, and 25 participants chose not to specify their sexual orientation (these individuals were 
excluded from analyses). Suicide attempts were reported by $n=131(17.8 \%)$ participants and NSSI was reported by 332 (45.2\%) participants. LGB individuals had a significantly higher rate of NSSI ( $65 \%$ vs. $41 \%)$ and SA (35\% vs. $14 \%)$ than non-LGB individuals $(p s<.05)$. Descriptive statistics for the four mediator variables (anxiety and depressive symptoms, thwarted belongingness, self-esteem) are reported in Table 1.

\section{TABLE 1 ABOUT HERE}

\section{Measurement Model}

The measurement model, featuring four correlated latent variables (anxiety and depressive symptoms, thwarted belongingness, self-esteem), initially showed only moderate fit, $X^{2}(98)=650.34, \mathrm{RMSEA}=.09(90 \% \mathrm{CI}: .08, .09), \mathrm{CFI}=.92, \mathrm{TLI}=.90, \mathrm{SRMR}=.05$. Allowing the error terms associated with two conceptually similar items on the self-esteem scale ("There are many things I like about myself"; "I like myself"), and thwarted belongingness scale ("I feel disconnected from other people", "I often feel like an outsider in social gatherings") to correlate led to good fit with the data, $X^{2}(96)=370.87$, RMSEA $=.06$ $(90 \%$ CI: .06, .07), CFI $=.96, \mathrm{TLI}=.95, \mathrm{SRMR}=.05$, with all standardised loadings $>.60$. Latent correlations between variables are reported in Table 2.

\section{TABLE 2 HERE}

\section{NSSI}

Table 3 presents the $\mathrm{AIC}_{\mathrm{c}}$, adjusted $\mathrm{BIC}$, ORs and associated $95 \%$ confidence intervals for all Models and predictors. In Model 1, LGB status was associated with a higher risk of NSSI. Model 3, which included both direct and indirect (via thwarted belongingness and self-esteem) associations between LGB status and NSSI, was the best fitting. Thus, LGB status remained associated with NSSI even after mediators were taken into account, though the strength of this association was slightly reduced. Self-esteem, but not thwarted belongingness (where there was also no trend of an effect), was significantly associated with 
self-harm, and was also a significant mediator (See Table 4). The addition of anxiety and depressive symptoms to the model (Model 4) led to poorer model fit. Across the models, removal of a single potential outlier based on log likelihood distances made no difference to results.

TABLE 3 ABOUT HERE

\section{TABLE 4 ABOUT HERE}

SA

The results for SA followed the same pattern. Once again, Model 3, which included both direct and indirect associations (via thwarted belongingness and self-esteem) with SA, showed the best fit to the study data of the three models. Self-esteem was significantly associated with SA, though with a smaller effect size than for NSSI. Thwarted belongingness was also associated with a greater risk of SA. For both thwarted belongingness and selfesteem, the indirect effects did not quite reach significance $(p=.06-.07)$, though the total indirect effect remained significant $(p<.01)$. As with NSSI, the addition of anxiety and depressive symptoms to the model (Model 4) led to poorer model fit. Across the models, removal of a single potential outlier based on log likelihood distances made no difference to results.

\section{Discussion}

The aim of this study was to examine the association between LGB status and selfharm in a UK student population, and to determine whether a set of four psychological variables mediated this association (depression, anxiety, belongingness, self-esteem). We examined these associations separately for NSSI and SA. In both instances LGB status remained associated with an elevated risk of self-harm even after accounting for mediating factors. This suggests that other variables, not included in this study, may also be important in accounting for the elevated self-harm risk in the LGB population. In particular, it may be that 
social factors, such as discrimination or marginalisation remain important even after these psychological factors are accounted for. Psychological factors, namely self-esteem and (in the case of SA but not NSSI) thwarted belongingness, did explain some of this association and were correlated with the risk of self-harm. Notably, including anxiety and depressive symptoms into the model as further mediators worsened fit, suggesting that these variables may have little added explanatory value over and above self-esteem and thwarted belongingness. Self-esteem and depressive symptoms had large latent correlations (see Table 2) which may explain why depressive symptoms added little to the model.

The results for NSSI and SA followed a similar pattern and so suggest that common processes may be operating in both cases. However, some differences were apparent. In particular thwarted belongingness had no relationship with NSSI, but was associated with SA. The concept of thwarted belongingness was initially developed to explain suicidal behaviour (Van Orden et al., 2010), not NSSI, and so these cognitions may be particularly linked to suicidal behaviour rather than self-harm in general. However, other research has supported a positive relationship between belongingness and NSSI (Assavedo \& Anestis, 2016), countering this possibility. Further investigation of these constructs with regards to LGB status and self-harm, including both SA and NSSI, would be beneficial.

This research suggests thwarted belongingness may account for the link between LGB status and suicide attempts, providing support for the IPTS. This research also supports the potential to integrate this model within a minority stress framework, in order to explain the heightened risk of suicidal behaviour seen in LGB individuals. Within this study we focused on a single construct from IPTS, belongingness, which we judged was most at threat from minority stress. However, it would be valuable to test a fuller integration of IPTS and minority stress theory (see Muehlenkamp et al., 2015). This research supports the role of selfesteem in understanding both NSSI and suicidal behaviour. Self-esteem, or self-concept more 
broadly, appears important from both a minority stress perspective and within recent models of self-injury (Haskings et al., 2017; Hatzenbuehler, 2009). Haskings and colleagues suggest other factors, less clearly linked to minority stress and LGB status, such as the expectations individuals have about self-injury and its consequences, which may potentially moderate the association between self-esteem and self-harm seen in this study. Thus, whilst the psychological variables in this study were chosen a priori on a theoretical basis, a range of other psychological variables known to be linked to self-harm were not included in the current study, but could be considered in future research. It would also be of value to investigation whether these psychological variables help explain elevated self-harm risk seen in other marginalised groups (e.g. Hughes, Knowles, Dhingra, Nicholson, \& Taylor, 2018).

Strengths of the study include the large sample, focus on a UK population, and systematic approach to analysis, including the explicit modelling of mediators. However, a number of limitations require mention. The assessment of LGB status was a simple categorical variable that did not allow a more nuanced assessment of sexual orientation, which is better seen as a continuum. Moreover, small numbers in sexual orientation subgroups (i.e. gay, lesbian, bisexual) limited our ability to look at these distinctions, but important differences may exist (Batejan et al., 2014). The study focused on lifetime presence of suicide attempts and NSSI. As such the reported associations are possibly indicative of broad patterns of risk within the student population but are not informative about proximal triggers or predictors of self-harm behaviours, or about determinants of severity. Likewise the cross-sectional nature of associations prevents any inferences around the direction of effect. Though it seems improbable that sexual orientation would be a consequence of a history of self-harm behaviour, it may be that the psychological variables examined are consequences rather than causes of self-harm behaviour. Thus, whilst results were largely consistent with 
our theoretical suppositions, longitudinal studies would be beneficial in elucidating the direction of relationships.

It has been argued that minority status can also confer resilience to psychological difficulties (Meyer, 2003). Clearly, not every LGB student experiences low self-esteem, and so the social and psychological factors that might influence whether this occurs are important. It is likely the social attitudes and messages one is exposed to are important here, as well compatibility of sexuality identity with other importance influences in one's life (e.g. religious context; Gibbs \& Goldbach, 2015). Whilst the current study assessed self-esteem, more specific constructs related to self-concept are suggested by minority stress theory, including internalised homophobia and perceived stigma, were not assessed. Homophobic and biphobic violence was also not assessed but has been identified in past research as a risk factor for self-harm (e.g. Ferlatte, Dulai, Hottes, Trussler \& Marchland, 2015). Future research should consider these additional variables in better understanding self-harm risk in the LGB population.

The current study supports the assertion that UK LGB students are at an elevated risk of self-harm, including both SA and NSSI. This finding mirrors data form US LGB young people and supports the view this population may benefit from focused prevention and intervention efforts (Haas et al., 2011). The findings also lend weight to the idea that psychological factors may account for the association between LGB status and self-harm (Hatzenbuehler, 2009; Meyer, 2003) and, as such, interventions directed at these psychological mediators may help to reduce self-harm risk in this population. In particular, self-esteem emerged as an important variable. Self-esteem may be particularly adversely affected in those who are struggling in accepting or sharing their sexuality with others, or who are exposed to discrimination and negative attitudes. It has been noted that evidence is lacking for self-harm prevention interventions aimed at LGB individuals (Marshall, 2016). A 
multifaceted approach to prevention and intervention may be well suited here. At a societal level, working to reduce discrimination and improve acceptance of LGB individuals through public policy and media campaigns may be helpful in reducing any impact on self-esteem (Cook, Purdie-Vaughns, Meyer, \& Busch, 2014; Meyer, 2003). Suicide prevention attempts aimed at LGB students have included training and awareness programmes designed to change attitudes and remove the environmental stressors associated with LGB status (e.g. homophobic and biphobic behaviour; Johnson, Oxednine, Taub \& Robertson, 2013). Whilst potentially helpful, it has been noted that such programmes can also reinforce the "victim" status of LGB individuals and fail to address the underlying social and culturally factors that drive problems like homophobic bullying (Payne \& Smith, 2017). Based on our data, programmes which help promote self-esteem (e.g. gay affirmative approaches; Craig, Austin \& Alessi, 2013) may be particularly helpful in preventing self-harm. At an individual level, psychological interventions that help improve self-esteem may be helpful for those particularly at risk (Taylor \& Montgomery, 2007). There is evidence that therapies including cognitive behavioural approaches, may help improve self-esteem and prevent self-harm (Slee Garnefski, Leeden, Arensman \& Spinhoven, 2008). However, such approaches may require adaption to better work with the challenges faced by LGB individuals (Craig, Austin \& Alessi, 2013). A recent UK study of LGBT young people and suicidality found that participants were reluctant to use mainstream services and preferred support provided in a LGBT setting (McDermott, Hughes, \& Rawlings, 2018). There is preliminary evidence that more actively self-critical ways of relating to oneself may be particularly problematic with regards to the risk of self-harm (Forrester et al., 2017). As such these individuals may be an important subgroup to further support through specific psychological intervention. 


\section{References}

Aranmolate, R., Bogan, D. R., Tiffany Hoard, \& Mawsomolate, A. R. (2017). Suicide Risk Factors among LGBTQ Youth: Review. JSM Schizophrenia, 2, 1011-1015. Retrieved from https://www.researchgate.net/publication/317582401_Suicide_Risk_Factors_among_ LGBTQ_Youth_Review

Assavedo, B. L., \& Anestis, M. D. (2016) The relationship between non-suicidal self-injury and both perceived burdensomeness and thwarted belongingness. Journal of Psychopathology \& Behavioral Assessment, 38, 251-257. doi:10.1007/s10862-0159508-8

Baams, L., Grossman, A. H., \& Russell, S. T. (2015). Minority stress and mechanisms of risk for depression and suicidal ideation among Lesbian, Gay, and Bisexual Youth. Developmental Psychology, 51, 688-696. doi:10.1037/a0038994

Batejan, K. L., Jarvi, S. M., \& Swenson, L. P. (2015). Sexual orientation and non-suicidal self-injury: A meta-analytic review. Archives of Suicide Research, 19, 131-150. doi:10.1080/13811118.2014.957450

Baumeister, R. F., \& Leary, M. R. (1995). The need to belong: Desire for interpersonal attachments as a fundamental human motivation. Psychological bulletin, 117, 497529.

Bergen, H., Hawton, K., Waters, K., Ness, J., Cooper, J., Steeg, S., \& Kapur, N. (2012). Premature death after self-harm: A multicentre cohort study. The Lancet, 380, 15681574. doi:10.1016/S0140-6736(12)61141-6

Brennan, C., Worrall-Davies, A., McMillan, D., Gilbody, S., \& House, A. (2010). The Hospital Anxiety and Depression Scale: A diagnostic meta-analysis of case-finding ability. J Psychosom Res, 69, 371-378. doi:10.1016/j.jpsychores.2010.04.006 
Burnham, K. P., \& Anderson, D. R. (2004). Multimodel inference: Understanding AIC and BIC in model selection. Sociological Methods \& Research, 33, 261-304. doi:10.1177/0049124104268644

Butler, A. M., \& Malone, K. (2013). Attempted suicide v. non-suicidal self-injury: Behaviour, syndrome or diagnosis? The British Journal of Psychiatry, 202, 324-325. doi:10.1192/bjp.bp.112.113506

Byrne, B. (2001). Structural equation modelling with AMOS: Basic concepts, applications and programming. London: Lawrence Erlbaum Associates.

Chu, C., Buchman-Schmitt, J. M., Stanley, I. H., Hom, M. A., Tucker, R. P., Hagan, C. R., . . . Joiner, T. E. (2017). The interpersonal theory of suicide: A systematic review and meta-analysis of a decade of cross-national research. Psychological bulletin, 143, 1313-1345. doi:10.1037/bul0000123

Cook, J. E., Purdie-Vaughns, V., Meyer, I. H., \& Busch, J. T. A. (2014). Intervening within and across levels: A multilevel approach to stigma and public health. Social Science \& Medicine, 103, 101-109. doi:https://doi.org/10.1016/j.socscimed.2013.09.023

Craig, S. L., Austin, A., \& Alessi, E. (2013). Gay affirmative cognitive behavioral therapy for sexual minority youth: A clinical adaptation. Clinical Social Work Journal, 41, 258266. doi: 10.1007/s 10615-012-0427-9

Cramer, R. J., Stroud, C. H., Fraser, T., \& Graham, J. (2014). A trait-interpersonal analysis of suicide proneness among lesbian, gay, and bisexual community members. Suicide and Life-Threatening Behavior, 44, 601-615. doi:10.1111/sltb.12092

Department of Health. (2017). Preventing suicide in England: Third progress report of the cross-government outcomes strategy to save lives.: Department of Health.

Department of Health, \& Department of Education. (2017). Transforming children and young people's mental health provision: A green paper. 
Enders, C. K., \& Tofighi, D. (2008). The impact of misspecifying class-specific residual variances in growth mixture models. Structural Equation Modeling: A Multidisciplinary Journal, 15, 75-95. doi:10.1080/10705510701758281

Ferlatte, O., Dulai, J., Hottes, T. S., Trussler, T., \& Marchland, R. (2015). Suicide related ideation and behaviour among Canadian gay and bisexual men: A syndemic analysis. BMC Public Health, 15, 597-606. doi: 10.1186/s12889-015-1961-5

Forrester, R. L., Slater, H., Jomar, K., Mitzman, S., \& Taylor, P. J. (2017). Self-esteem and non-suicidal self-injury in adulthood: A systematic review. Journal of Affective Disorders, 221, 172-183. doi:10.1016/j.jad.2017.06.027

Fox, K. R., Franklin, J. C., Ribeiro, J. D., Kleiman, E. M., Bentley, K. H., \& Nock, M. K. (2015). Meta-analysis of risk factors for nonsuicidal self-injury. Clinical Psychology Review, 42, 156-167. doi:10.1016/j.cpr.2015.09.002

Freedenthal, S., Lamis, D. A., Osman, A., Kahlo, D., \& Gutierrez, P. M. (2011). Evaluation of the psychometric properties of the Interpersonal Needs Questionnaire-12 in samples of men and women. Journal of Clinical Psychology, 67, 609-923. doi:10.1002/jclp.20782

Gibbs, J. J., \& Goldbach, J. (2015). Religious conflict, sexual identity, and suicidal behaviors among LGBT young adults. Archives of Suicide Research, 19, 472-488. doi:10.1080/13811118.2015.1004476

Goldman-Mellor, S. J., Caspi, A., Harrington, H., Hogan, S., Nada-Raja, S., Poulton, R., \& Moffitt, T. E. (2014). Suicide attempt in young people: A signal for long-term health care and social needs. JAMA Psychiatry, 71, 119-127. doi:10.1001/jamapsychiatry.2013.2803

Haas, A. P., Eliason, M., Mays, V. M., Mathy, R. M., Cochran, S. D., D’augelli, A. R., . . Clayton, P. J. (2011). Suicide and suicide risk in lesbian, gay, bisexual, and 
transgender populations: Review and recommendations. Journal of homosexuality, 58, 10-51. doi:10.1080/00918369.2011.534038

Haseldon, L., \& Joloza, T. (2009). Measuring sexual identity: A guide for researchers. Newport: Office for National Statistics.

Hasking, P., Momeni, R., Swannell, S., \& Chia, S. (2008). The nature and extent of nonsuicidal self-injury in a non-clinical sample of young adults. Archives of Suicide Research, 12, 208-218. doi:10.1080/13811110802100957

Hasking. P., Whitlock, J., Voon, D., \& Rose, A. (2017). A cognitive-emotional modle of NSSI: Using emotion regulstion and cognitive processes to explain why people selfinjure. Cogniiton \& Emotion, 31, 1543-1556. doi: 10.1080/02699931.2016.1241219

Hatzenbuehler, M. L. (2009). How does sexual minority stigma "get under the skin"? A psychological mediation framework. Psychological bulletin, 135, 707-730. doi:10.1037/a0016441

Hawton, K., Bergen, H., Cooper, J., Turnbull, P., Waters, K., Ness, J., \& Kapur, N. (2015). Suicide following self-harm: findings from the Multicentre Study of self-harm in England, 2000-2012. Journal of Affective Disorders, 175, 147-151. doi:10.1016/j.jad.2014.12.062

Hawton, K., Rodham, K., Evans, E., \& Weatherall, R. (2002). Deliberate self harm in adolescents: self report survey in schools in England. BMJ, 325, 1207 - 1211.

Hegna, K., \& Wichstrøm, L. (2007). Suicide attempts among Norwegian gay, lesbian and bisexual youths: General and specific risk factors. Acta Sociologica, 50, 21-37. doi:10.1177/0001699307074880

Hill, R. M., \& Pettit, J. W. (2012). Suicidal ideation and sexual orientation in college students: The roles of perceived burdensomeness, thwarted belongingness, and 
perceived rejection due to sexual orientation. Suicide and Life-Threatening Behavior, 42, 567-579. doi:10.1111/j.1943-278X.2012.00113.x

Hu, L., \& Bentler, P. M. (1999). Cutoff criteria for fit indexes in covariance structure analysis: Conventional criteria versus new alternatives. Structural Equation Modeling: A Multidisciplinary Journal, 6, 1-55. doi:10.1080/10705519909540118

Hughes, M. A., Knowles, S. F., Dhingra, K., Nicholson, H. L., \& Taylor, P. J (2018). This corrosion: A systematic review of the association between alternative subcultures and the risk of self-harm and suicide. British Journal of Clinical Psychology. doi:doi:10.1111/bjc.12179

Husain, M., Waheed, W., \& Husain, N. (2006). Self-harm in British South Asian women: Psychosocial correlates and strategies for prevention. Annuals of General Psychiatry, 5, 7. doi:10.1186/1744-859X-5-7

Kapur, N., Cooper, J., O’Connor, R. C., \& Hawton, K. (2013). Non-suicidal self-injury v. attempted suicide: New diagnosis or false dichotomy? British Journal of Psychiatry, 202, 326-328. doi:10.1192/bjp.bp.112.116111

Kashubeck-West, S., Szymanski, D., \& Meyer, J. (2008). Internalized heterosexism: Clinical implications and training considerations. The Counseling Psychologist, 36, 615-630. doi:10.1177/0011000007309634

Kline, R. B. (2011). Principles and practice of structural equation modeling (3rd ed.). New York: The Guilford Press.

Lambe, J., Cerezo, A., \& O'Shaughnessy, T. (2017). Minority stress, community involvement, and mental health among bisexual women. Psychology of Sexual Orientation and Gender Diversity, 4, 218-226. doi:10.1037/sgd0000222 
Little, T. D., Cunningham, W. A., Shahar, G., \& Widaman, K. F. (2002). To parcel or not to parcel: Exploring the question, weighing the merits. Structural Equation Modeling: A Multidisciplinary Journal, 9, 151-173.doi:10.1207/S15328007SEM0902_1

Little, T. D., Rhemtulla, M., Gibson, K., \& Schoemann, A. M. (2013). Why the items versus parcels controversy needn't be one. Psychological Methods, 18, 285-300. doi:10.1037/a0033266

Maniglio, R. (2011). The role of child sexual abuse in the etiology of suicide and non-suicidal self-injury. Acta Psychiatr Scand, 124, 30-41. doi:10.1111/j.1600-0447.2010.01612.x

Marshall, A. (2016). Suicide prevention interventions for sexual \& gender minority youth: An unmet need. Yale Journal of Biology and Medicine, 89, 205-213. Retrieved from https://www.ncbi.nlm.nih.gov/pmc/articles/PMC4918883/

McDermott, E., Hughes, E., \& Rawlings, V. (2017). The social determinants of lesbian, gay, bisexual and transgender youth suicidality in England: A mixed methods study. Journal of Public Health, 1-8. doi:10.1093/pubmed/fdx135

McDermott, E., Hughes, E., \& Rawlings, V. (2018). Norms and normalisation: Understanding lesbian, gay, bisexual, transgender and queer youth, suicidality and help-seeking. Culture, Health \& Sexuality, 20, 156-172.

doi:10.1080/13691058.2017.1335435

McGee, R., \& Williams, S. (2000). Does low self-esteem predict health compromising behaviours among adolescents? Journal of Adolescence, 23, 569-582. doi:10.1006/jado.2000.0344

McLaren, S. (2016). The relationship between living alone and depressive symptoms among older gay men: The moderating role of sense of belonging with gay friends. International Psychogeriatrics, 28, 1895-1901. doi:10.1017/S1041610216001241 
Meyer, I. H. (2003). Prejudice, social stress, and mental health in lesbian, gay, and bisexual populations: Conceptual issues and research evidence. Psychological Bulletin, 129, 674-697. doi:10.1037/0033-2909.129.5.674

Miranda-Mendizábal, A., Castellví, P., Parés-Badell, O., Almenara, J., Alonso, I., Blasco, M. J., . . Alonso, J. (2017). Sexual orientation and suicidal behaviour in adolescents and young adults: systematic review and meta-analysis. The British Journal of Psychiatry, 211, 77-87. doi:10.1192/bjp.bp.116.196345

Muehlenkamp, J. J., Hilt, L. M., Ehlinger, P. P., \& McMillan, T. (2015). Nonsuicidal selfinjury in sexual minority college students: a test of theoretical integration. Child and adolescent psychiatry and mental health, 9(1), 16. doi:10.1186/s13034-015-0050-y

Muthén, L. K., \& Muthén, B. O. (1998-2012). Mplus user's guide. Seventh edition. Los Angeles, CA: Muthén \& Muthén.

National Collaborating Centre for Mental Health. (2004). Self-harm: The short-term physical and psychological management and secondary prevention of self-harm in primary and secondary care: National Institue for Clinical Excellence.

Nock, M. K., Holmberg, E. B., Photos, V. I., \& Michel, B. D. (2007). Self-Injurious Thoughts and Behaviors Interview: Development, reliability, and validity in an adolescent sample. Psychological Assessessment, 19, 309-317. doi:10.1037/10403590.19.3.309

Osman, A., Gutierrez, P. M., Muehlenkamp, J. J., Dix-Richardson, F., Barrios, F. X., \& Kopper, B. A. (2004). Suicide Resilience Inventory-25: Development and preliminary psychometric properties. Psychological Reports, 94, 1349-1360. doi:10.2466/pr0.94.3c.1349-1360 
Payne, E., Smith, M. (2013). LGBTQ Kids, School Safety, and Missing the Big Picture: How the Dominant Bullying Discourse Prevents School Professionals from Thinking about Systemic Marginalization or ... Why We Need to Rethink LGBTQ Bullying. QED: A Journal in GLBTQ Worldmaking, Fall 2013, 1-36. Retrieved from http://www.jstor.org/stable/10.14321/qed.0001

Pitoňák, M. (2017). Mental health in non-heterosexuals: Minority stress theory and related explanation frameworks review. Mental Health \& Prevention, 5, 63-73. doi:https://doi.org/10.1016/j.mhp.2016.10.002

Rasmussen, S., Hawton, K., Philpott-Morgan, S., \& O'Connor, R. C. (2016). Why do adolescents self-harm? Crisis, 37, 176-183. doi:10.1027/0227-5910/a000369

Reinherz, H. Z., Giaconia, R. M., Silverman, A. B., Friedman, A., Pakiz, B., Frost, A. K., \& Cohen, E. (1995). Early psychosocial risks for adolescent suicidal ideation and attempts. Journal of the American Academy of Child \& Adolescent Psychiatry, 34, 599-611. doi:http://dx.doi.org/10.1097/00004583-199505000-00012

Ribeiro, J. D., Franklin, J. C., Fox, K. R., Bentley, K. H., Kleiman, E. M., Chang, B. P., \& Nock, M. K. (2016). Self-injurious thoughts and behaviors as risk factors for future suicide ideation, attempts, and death: A meta-analysis of longitudinal studies. Psychological Medicine, 46, 225-236. doi:10.1017/S0033291715001804

Rosenberg, M. (1965). Society and the adolescent self-image. Princeton, New Jersey: Princeton University Press.

Satorra, A., \& Bentler, E. M. (1994). Corrections to test statistics and standard enors in covariance structure analysis. In A. v. Eye \& C. C. Clogg (Eds.), Latent variables analysis: Applications for developmental research (pp. 399-419). Thousand Oaks, CA: Sage. 
Semlyen, J., King, M., Varney, J., \& Hagger-Johnson, G. (2016). Sexual orientation and symptoms of common mental disorder or low wellbeing: Combined meta-analysis of 12 UK population health surveys. BMC Psychiatry, 16, 67. doi:10.1186/s12888-016$0767-\mathrm{z}$

Slee, N., Garnefski, N., van der Leeden, R., Arensman, E., \& Spinhoven, P. (2008). Cognitive-behavioural intervention for self-harm: Randomised controlled trial. British Journal of Psychiatry, 192, 202-211. doi: 10.1192/bjp.bp.107.037564.

Sowe, B. J., Taylor, A. J., \& Brown, J. (2017). Religious anti-gay prejudice as a predictor of mental health, abuse, and substance use. American Journal of Orthopsychiatry, 87, 690-703. doi:10.1037/ort0000297

Sue, D. W. (2010). Sexual orientation microaggressions and heterosexism. In D. W. Sue (Ed.), Microaggressions in everyday life: Race, gender, and sexual orientation (pp. 184-206). Hoboken, NJ: Wiley.

Tatnell, R., Kelada, L., Hasking, P., \& Martin, G. (2014). Longitudinal analysis of adolescent NSSI: The role of intrapersonal and interpersonal factors. Journal of Abnormal Child Psychology, 42, 885-896. doi:10.1007/s10802-013-9837-6

Taylor, P. J., Jomar, K., Dhingra, K., Forrester, R., Shahmalak, U., \& Dickson, J. M. (2018). A meta-analysis of the prevalence of different functions of non-suicidal self-injury. Journal of Affective Disorders, 227, 759-769. doi:10.1016/j.jad.2017.11.073

Taylor, T., \& Montgomery, P. (2007). Can cognitive-behavioral therapy increase self-esteem among depressed adolescents? A systematic review. Retrieved from https://www.ncbi.nlm.nih.gov/pubmedhealth/PMH0024773/

Van Orden, K. A., Cukrowicz, K. C., Witte, T. K., \& Joiner, T. E. (2012). Thwarted belongingness and perceived burdensomeness: Construct validity and psychometric 
properties of the interpersonal needs questionnaire. Psychological Assessment, 24, 197-215. doi:10.1037/a0025358

Van Orden, K. A., Witte, T. K., Cukrowicz, K. C., Braithwaite, S. R., Selby, E. A., \& Joiner, T. E., Jr. (2010). The interpersonal theory of suicide. Psychological Review, 117, 575600. doi:10.1037/a0018697

Van Orden, K. A., Witte, T. K., Gordon, K. H., Bender, T. W., \& Joiner, T. E., Jr. (2008). Suicidal desire and the capability for suicide: Tests of the interpersonal-psychological theory of suicidal behavior among adults. Journal of Consulting \& Clinical Psychology, 76, 72-83. doi:10.1037/0022-006X.76.1.72

Warner, J., McKeown, E., Griffin, M., Johnson, K., Ramsay, A., Cort, C., \& King, M. (2004). Rates and predictors of mental illness in gay men, lesbians and bisexual men and women. Results from a survey based in England and Wales, 185, 479-485. doi:10.1192/bjp.185.6.479

Woodward, E. N., Wingate, L. R., Gray, T. W., \& Pantalone, D. W. (2014). Evaluating thwarted belongingness and perceived burdensomeness as predictors of suicidal ideation in sexual minority adults. Psychology of Sexual Orientation and Gender Diversity, 1, 234 -243. doi:10.1037/sgd0000046

Ybarra, M. L., Mitchell, K. J., Palmer, N. A., \& Reisner, S. L. (2015). Online social support as a buffer against online and offline peer and sexual victimization among U.S. LGBT and non-LGBT youth. Child Abuse \& Neglect, 39, 123-136. doi:https://doi.org/10.1016/j.chiabu.2014.08.006

Young, R., Riordan, V., \& Stark, C. (2011). Perinatal and psychosocial circumstances associated with risk of attempted suicide, non-suicidal self-injury and psychiatric service use. A longitudinal study of young people. BMC Public Health, 11, 875-875. doi:10.1186/1471-2458-11-875 
Yuan, K. H., \& Bentler, P. M. (2000). Three likelihood-based methods for mean and covariance structure analysis with nonnormal missing data. Sociological Methodology, 30, 165-200. doi: 10.1111/0081-1750.00078

Zigmond, A. S., \& Snaith, R. P. (1983). The hospital anxiety and depression scale. Acta Psychiatr Scand, 67, 361-370. doi: 10.1111/j.1600-0447.1983.tb09716.x 
Disclosure Statement

Not Applicable 
Table 1

Descriptive Statistics for Psychological Mediator Variables

\begin{tabular}{llll}
\hline Variable & Total sample $M$ & LGB group $M$ & Non-LGB group $M$ \\
& $(S D)$ & $(S D)$ & $(S D)$ \\
\hline Depressive symptoms & $12.46(4.14)$ & $13.83(4.27)$ & $12.19(4.06)$ \\
Anxiety symptoms & $10.06(4.50)$ & $11.72(4.26)$ & $9.74(4.47)$ \\
Thwarted & $18.03(7.99)$ & $22.06(6.94)$ & $17.24(7.95)$ \\
Belongingness & & & \\
Self-esteem & $19.59(6.79)$ & $17.06(6.92)$ & $20.10(6.65)$ \\
\hline
\end{tabular}

Scores based on simple sum of items; Depressive symptoms scores range from 7 to 26 ;

Anxiety symptoms scores range from 0 to 21; Belongingness scores range from 5 to 35; Selfesteem scores range from 5 to 30 . 
Table 2

Inter-Correlations between Latent Continuous Variables

\begin{tabular}{llll}
\hline Variable & 2 & 3 & 4 \\
& & & \\
\hline 1. Depressive symptoms & .69 & .75 & -.80 \\
2. Anxiety symptoms & & .55 & -.65 \\
3. Belongingness & & & -.73 \\
4. Self-esteem & & & \\
\end{tabular}

All associations significant at $P<.001$ 
Table 3

AICc, BIS and Odds Ratios for all Estimated Models

\section{OR $(95 \% \mathrm{CI})$}

\begin{tabular}{|c|c|c|c|c|c|c|}
\hline $\mathrm{AICc}$ & $\begin{array}{l}\text { adjusted } \\
\text { BIC }\end{array}$ & LGB status & Belongingness & Self-esteem & $\begin{array}{l}\text { Depressive } \\
\text { symptoms }\end{array}$ & $\begin{array}{l}\text { Anxiety } \\
\text { symptoms }\end{array}$ \\
\hline
\end{tabular}

\begin{tabular}{|c|c|c|c|c|c|c|c|}
\hline \multicolumn{8}{|c|}{ Non-Suicidal Self-Injury } \\
\hline M1 & 36457.59 & 36527.41 & $\begin{array}{l}2.67(1.77, \\
4.03)^{*}\end{array}$ & - & - & - & - \\
\hline M2 & 36347.84 & 36420.65 & - & $1.01(0.76,1.35)$ & $\begin{array}{l}0.37(0.28 \\
0.50)^{*}\end{array}$ & - & - \\
\hline M3 & 36341.12 & 36414.91 & $2.03(1.29,3.19)$ & $0.94(0.70,1.26)$ & $\begin{array}{l}0.36(0.27 \\
0.49)^{*}\end{array}$ & - & - \\
\hline M4 & 36355.80 & 36433.45 & $\begin{array}{l}1.94(1.23, \\
3.07)^{*}\end{array}$ & $0.93(0.64,1.36)$ & $\begin{array}{l}0.45(0.31 \\
0.65)^{*}\end{array}$ & $0.91(0.56,1.50)$ & $1.58(1.16,2.15)^{*}$ \\
\hline \multicolumn{8}{|c|}{$\underline{\text { Suicide Attempt }}$} \\
\hline M1 & 36134.48 & 36204.30 & $\begin{array}{l}3.46(2.21, \\
5.39)^{*}\end{array}$ & - & - & - & - \\
\hline M2 & 36096.74 & 36169.55 & - & $1.62(1.14,2.32)$ & $0.63(0.45,0.89)$ & - & - \\
\hline M3 & 36086.01 & 36159.80 & $\begin{array}{l}2.46(1.51, \\
4.02)^{*}\end{array}$ & $\begin{array}{l}1.48(1.03, \\
2.14)^{*}\end{array}$ & $\begin{array}{l}0.62(0.44, \\
0.88)^{*}\end{array}$ & - & - \\
\hline M4 & 36109.04 & 36186.68 & $\begin{array}{l}2.52(1.53 \\
4.16)^{*}\end{array}$ & $1.30(0.82,2.07)$ & $0.79(0.49,1.29)$ & $1.41(0.78,2.56)$ & $1.07(0.70,1.63)$ \\
\hline
\end{tabular}


$* P<.01$; To aid interpretations of effect sizes, variances of latent variables have been fixed at 1 , rather than fixing a factor loading to enable model identification. 
Table 4

Summary of Unstandardised Indirect Effects

\begin{tabular}{lll}
\hline & NSSI & SA \\
\hline Total indirect & $0.15(-0.01,0.31)$ & $0.22(0.08,0.35)$ \\
Belongingness & $-0.02(-0.12,0.08)$ & $0.13(-0.00,0.27)$ \\
Self-esteem & $0.17(0.02,0.33)$ & $0.08(-0.01,0.17)$ \\
\hline
\end{tabular}

$* P<.01$; Values are unstandardised regression coefficients and associated $95 \%$ Confidence

Intervals. Indirect effects taken from Model 3 in both cases, as the best fitting model. 